\title{
Dexibuprofen ameliorates peripheral and central risk factors associated with Alzheimer's disease in metabolically stressed APPswe/PS1dE9 mice
}

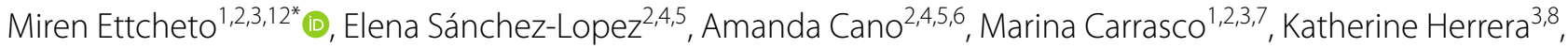 \\ Patricia R. Manzine ${ }^{9}$, Triana Espinosa-Jimenez ${ }^{1,2,3}$, Oriol Busquets ${ }^{10}$, Ester Verdaguer ${ }^{2,3,8}$, Jordi Olloquequi ${ }^{11}$, \\ Carme Auladell ${ }^{2,3,8}$, Jaume Folch ${ }^{2,7}$ and Antoni Camins $s^{1,2,3}$
}

\begin{abstract}
Background: Several studies stablished a relationship between metabolic disturbances and Alzheimer's disease (AD) where inflammation plays a pivotal role. However, mechanisms involved still remain unclear. In the present study, we aimed to evaluate central and peripheral effects of dexibuprofen (DXI) in the progression of AD in APPswe/PS1dE9 (APP/PS1) female mice, a familial AD model, fed with high fat diet (HFD). Animals were fed either with conventional chow or with HFD, from their weaning until their sacrifice, at 6 months. Moreover, mice were divided into subgroups to which were administered drinking water or water supplemented with DXI $\left(20 \mathrm{mg} \mathrm{kg}^{-1} \mathrm{~d}^{-1}\right)$ for 3 months. Before sacrifice, body weight, intraperitoneal glucose and insulin tolerance test (IP-ITT) were performed to evaluate peripheral parameters and also behavioral tests to determine cognitive decline. Moreover, molecular studies such as Western blot and RT-PCR were carried out in liver to confirm metabolic effects and in hippocampus to analyze several pathways considered hallmarks in AD.
\end{abstract}

Results: Our studies demonstrate that DXI improved metabolic alterations observed in transgenic animals fed with HFD in vivo, data in accordance with those obtained at molecular level. Moreover, an improvement of cognitive decline and neuroinflammation among other alterations associated with AD were observed such as beta-amyloid plaque accumulation and unfolded protein response.

Conclusions: Collectively, evidence suggest that chronic administration of DXI prevents the progression of AD through the regulation of inflammation which contribute to improve hallmarks of this pathology. Thus, this compound could constitute a novel therapeutic approach in the treatment of AD in a combined therapy.

Keywords: APPswe/PS1dE9, Alzheimer's disease, Dexibuprofen, Unfolded protein response, neuroinflammation, Synapsis, Cognitive deficits, High fat diet, Metabolic alterations, $\beta A$ plaques

\footnotetext{
*Correspondence: mirenettcheto@ub.edu

1 Department of Pharmacology, Toxicology and Therapeutic Chemistry, Faculty of Pharmacy and Food Science, University of Barcelona, Barcelona, Spain

Full list of author information is available at the end of the article
}

\section{Background}

Alzheimer's disease (AD) is a progressive neurodegenerative disease characterized by severe impairments of cognitive function leading to development of drastic dementia. For years, this pathology has been defined by the combined presence of amyloid- $\beta(\mathrm{A} \beta)$ plaques and original author(s) and the source, provide a link to the Creative Commons licence, and indicate if changes were made. The images or other third party material in this article are included in the article's Creative Commons licence, unless indicated otherwise in a credit line to the material. If material is not included in the article's Creative Commons licence and your intended use is not permitted by statutory regulation or exceeds the permitted use, you will need to obtain permission directly from the copyright holder. To view a copy of this licence, visit http://creativecommons.org/licenses/by/4.0/. The Creative Commons Public Domain Dedication waiver (http://creativeco mmons.org/publicdomain/zero/1.0/) applies to the data made available in this article, unless otherwise stated in a credit line to the data. 
neurofibrillary tangles composed by hyperphosphorylated Tau. However, the continuous increase of cases worldwide together with the failure of proposed treatments until now have located this pathology as one of the great health-care challenges of the twenty-first century, promoting new approach about its etiology and, therefore, about its therapeutic strategies.

In this regard, in the recent years, several studies have focused on the potential relationship between $\mathrm{AD}$ and metabolic disorders $[1,2]$, considering $\mathrm{AD}$ as a multifactorial disease. In fact, longitudinal studies have indicated worsening performance of specific abilities including working memory in patients with metabolic disorders [3, 4]. In line with this hypothesis, obesity and type 2 diabetes mellitus (T2DM) also have been associated to cognitive decline in several studies considering them as key contributors not only in cognitive alterations [5-8] but also in the development of $\mathrm{AD}[9,10]$. As a result, a new concept have been introduced by scientific community to define AD named "type 3 diabetes" [11, 12].

In this context, the association between T2DM and $\mathrm{AD}$ is very complex where several molecular pathways are interlinked such as insulin resistance, peripheral inflammatory response, and endoplasmic reticulum stress, among others [13]. Likewise, insulin resistance is one of the main hallmarks of obesity and T2DM which plays an essential role in the maintenance in the cell energy homeostasis. Surprisingly, the appearance of similar abnormalities in both, peripheral tissues of T2DM patients and $\mathrm{AD}$ brains has been demonstrated [14-17]. Moreover, $\mathrm{Wu}$ and coworkers have proven the existence of peripheral metabolic changes in plasma and liver of $\mathrm{AD}$ mice models, suggesting that AD development is not only caused by alterations in the brain but also that systemic impairment plays a key role in the pathology [18]. In fact, it has also been demonstrated that peripheral alterations in the insulin pathway observed in patients with T2DM contribute to alterations in brain insulin, leading to an increase of $A \beta$ accumulation and a decrease of its clearance, which induce neuronal damage and, therefore, cognitive decline, creating a vicious cycle of pathogenesis [19].

As it has been mentioned before, inflammation is involved not only metabolic disorders but also in $\mathrm{AD}$, and is considered a critical process in this pathology. However, its dual contribution to the disease adds complexity to the process. Moreover, increasing clinical and experimental studies have evidenced that acute and chronic systemic inflammatory pathologies may be associated with the risk and acceleration of $\mathrm{AD}$ [20]. In line with this hypothesis, numerous epidemiological studies have demonstrated that anti-inflammatory drugs can reduce the risk of development AD in more than 50\% fold [21-23], for this reason non-steroidal anti-inflammatory drugs are being one the research focus concerning to AD therapeutic strategy.

Ibuprofen (IBU) is one of the most used nonsteroidal anti-inflammatory drugs (NSAIDs) which has demonstrated promising results in decreasing hallmarks of $\mathrm{AD}$ [24], by contrast, its chronic intake has demonstrated multiple adverse effect such as gastric damage. For these reasons, our study has focused in the evaluation of dexibuprofen (DXI), the active enantiomer of IBU $[25,26]$, which has been demonstrated that it has not only a more powerful anti-inflammatory and analgesic effect compared to IBU but also less ulcerogenic side effects [27-30]. Therefore, taking these previous findings into account, and according to the Herrup hypothesis which suggests that peripheral inflammation could be one of the responsible of neuroinflammation associated to neurodegeneration, the aim of our study is to investigate the central and peripheral effects of DXI in the progression of $\mathrm{AD}$ and describe the involved mechanisms in APPswe/ PS1dE9 (APP/PS1) female mice, familial AD mice model, fed with high fat diet (HFD).

\section{Methods \\ Animals and treatment}

In this study, six-month old female APP/PS1 double transgenic mice were used. Female sex was chosen due to the fact that it has been reported that they produce a significantly higher amyloid burden and subsequent plaque deposition than their male counterparts [31]. Moreover, these transgenic mice express a Swedish (K594M/N595L) mutation of a chimeric mouse/human APP gene (mo/ huAPP695swe) together with the human exon-9-deleted variant of presenilin 1 (PS1-dE9). Animals were divided into 4 groups: (1) mice fed with conventional chow (APP/ PS1), (2) mice fed with conventional chow and additionally treated with DXI (APP/PS1 DXI), (3) mice fed with a palmitic acid-enriched high fat diet (APP/PS1 HFD) containing $45 \%$ of fat mainly from hydrogenated coconut oil (Research Diets Inc, New Brunswick, USA) (APP/PS1 HFD) and (4) mice fed with HFD and additionally treated with DXI (APP/PS1 HFD DXI). The drug was administered in drinking water at a dose of $20 \mathrm{mg} \mathrm{kg}^{-1} \mathrm{~d}^{-1}$ for 3 months, from mice aged 3 months old until their sacrifice at 6 months, as previously described [30]. At least, 10 animals per group were used for this study. All mice were given access to water and food ad libitum and kept under controlled light, temperature and humidity conditions. Every possible effort was made to reduce the number of animals used and minimize their suffering. Mice were treated in accordance with the European Community Council Directive 86/609/EEC and the procedures were 
established by the Department d'Agricultura, Ramaderia i Pesca of the Generalitat de Catalunya.

\section{Glucose and insulin tolerance test}

Intraperitoneal glucose tolerance test (IP-GTT) and insulin tolerance test (IP-ITT) were performed in accordance with the previously described guideline [32]. Briefly, mice were fasted, at least, for $6 \mathrm{~h}$ prior to carry out both procedures and at least 10 animals were used per group. Tail blood was collected at multiple time points. Blood glucose levels were assayed with Accu-Chek Aviva glucometer (Roche; Mannheim, Germany). Those animals in which blood glucose concentration reached values below $20 \mathrm{mg} / \mathrm{dl}$ were treated with glucose at a dose of $1 \mathrm{~g} / \mathrm{kg}$.

\section{Cognitive test}

\section{Morris water maze}

APP/PS1 mice were subjected to Morris water maze (MWM) test in order to assess the spatial memory and learning abilities as previously described by our group [33]. Acquired data were analyzed using SMART V3.0 (Panlab Harvard Apparatus, Germany) video tracking system, calculating results individually for each animal. At least, 10 animals per group were utilized.

\section{Novel object recognition test}

The novel object recognition test (NORT) was used for assessing the hippocampal-dependent recognition memory of mice as it has been previously detailed [34]. At least, 10 mice per condition were used. Data were analyzed by discrimination index (DI) which was calculated using the following equation:

$$
D I=\frac{\text { New object exploration time }- \text { old object exploration time }}{\text { total exploration time }}
$$

Data measured and represented in seconds.

\section{Immunofluorescence, S-thioflavin staining and enzymatic immunohistochemistry}

To perform these 3 techniques, $4-5$ mice were anesthetized by i.p. injection of ketamine $(100 \mathrm{mg} / \mathrm{kg})$ and xylacine $(10 \mathrm{mg} / \mathrm{kg})$ and perfused with $4 \%$ paraformaldehyde (PFA) diluted in $0.1 \mathrm{M}$ phosphate buffer (PB). Brains were removed and stored in the same solution overnight $(\mathrm{O} / \mathrm{N}) .24 \mathrm{~h}$ later, they were cryoprotected in $30 \%$ sucrose-PFA-PB solution for at least 1 day and samples were kept at $-80^{\circ} \mathrm{C}$ until their use. Coronal sections of $20 \mu \mathrm{m}$ of thickness were obtained using a cryostat (Leica Microsystems, Wetzlar, Germany).

To perform the experiments, free-floating technique was used for all of them. Immunoshistochemistry and S-thioflavin protocols were carried out as previously described [35]. Briefly, free-floating sections were rinsed in phosphate-buffered saline (PBS) $(\mathrm{pH} 7,2)$ prior to preincubation in a blocking solution (10\% fetal bovine serum (FBS), $1 \%$ of triton X-100 in PBS at room temperature for $1 \mathrm{~h}$ and then, they were incubated $\mathrm{O} / \mathrm{N}$ at $4{ }^{\circ} \mathrm{C}$ with the corresponding primary antibody and immediately with the corresponding secondary antibody for $2 \mathrm{~h}$ at room temperature.

Enzymatic immunohistochemistry was performed as previously described by our group [36]. All the antibodies used for these experiments have been described in Table 1.

All the samples were mounted onto gelatinized slides with Fluoromount G (EMS). Image acquisition was performed with an epifluorescence microscope (BX41, Laboratory Microscope, NY-Olympus America Inc.). For plaque quantification, similar and comparable histological areas, particularly from the cortex, were selected. Immunohistochemistry labeling was analyzed through ImageJ software.

\section{Immunoblot analysis}

For Immunoblot, 5-6 mice from each experimental group were sacrificed by cervical dislocation and their hippocampus and liver were dissected. Total protein extraction was carried out by homogenizing tissue samples in lysis buffer $(50 \mathrm{mM}$ Tris $\mathrm{HCl} \mathrm{pH}: 7.4,150 \mathrm{mM}$ $\mathrm{NaCl}, 5 \mathrm{mM}$ EDTA, 1\%Triton X-100) containing a protease and phosphatase inhibitor mixture (Complete, Roche Diagnostics, Barcelona, Spain). Protein concentration was determined by Pierce BCA Protein Assay Kit (Pierce Company, Rockford, MI, USA) and aliquot of samples containing $10 \mu \mathrm{g}$ were used for performing western blot procedure as previously described by our group [34]. The antibodies employed in the experiment are listed in Table 2. Finally, blots were exposed to Chemiluminescence-based detection kit in a Chemi$\mathrm{doc}^{\mathrm{TM}}$ XRS + Molecular Imager detection system (BioRad), through Image Lab ${ }^{\mathrm{TM}}$ image analysis software (version 5.2.1). Obtained results were normalized to the

Table 1 Primary and secondary antibodies for immunohistochemistry and immnunofluorescence

\begin{tabular}{ll}
\hline Protein & Reference \\
\hline DBN1 & ABN 207 (Merck Millipore) \\
GFAP & Z0334 (Dako) \\
IBA1 & O19-19,741 (Wako) \\
Synaptophisin & MO776 (Dako) \\
$2^{\text {nd }-a r y ~ A n t i-r a b b i t ~ I g G ~ B i o t i n ~ a n t i b o d y ~}$ & B8895-1ML (Sigma Millipore) \\
$\quad$ produced in goat & \\
$2^{\text {nd }-a r y ~ A l e x a F l u o r ~ 488 ~(G o a t ~ a n t i-m o u s e) ~}$ & A11001 (Life Technologies) \\
$2^{\text {nd } \text {-ary AlexaFluor 594 (Goat anti-rabbit) }}$ & A11080 (Life Technologies) \\
\hline
\end{tabular}


Table 2 Primary and secondary antibodies for Western Blotting

\begin{tabular}{ll}
\hline Protein & Reference \\
\hline ADAM10 & ab39177 (Abcam) \\
AKT & \#9272 (Cell Signaling Technology) \\
PAKT (S473) & $\# 4060$ (Cell Signaling Technology) \\
elF2a & \#9722 (Cell Signaling Technology) \\
pelF2a (S51) & \#9721 (Cell Signaling Technology) \\
GAPDH & MAB374 (Millipore) \\
GSK3ß & \#9315 (Cell Signaling Technology) \\
pGSK3ß (S9) & \#9336 (Cell Signaling Technology) \\
IREa & Sc 390,960 (Santa Cruz Biotechnology) \\
pIREa (S724) & NB100-2323 (Novusbio) \\
IRS2 & Ab134101 (Abcam) \\
pIRS2 (S731) & Ab3690 (Abcam) \\
$2^{\text {nd }-a r y ~ G o a t ~ a n t i-r a b b i t ~}$ & 31,460 (Invitrogen) \\
$2^{\text {nd }-a r y ~ G o a t ~ a n t i-m o u s e ~}$ & 31,430 (Invitrogen) \\
\hline
\end{tabular}

corresponding glyceraldehyde 3-phosphate dehydrogenase (GAPDH) and expressed in arbitrary units (a.u).

\section{Real time PCR}

Samples were obtained as described in the $2.5 \mathrm{Immu-}$ noblot test section where 4-6 animals were used. RNA extraction was performed by TRIsure-based extraction (Bloline $\mathrm{GmbH}$ ) as previously described by our group [34]. The RNA pellet was reconstituted in RNAse free water and RNA concentration was measured using a NanoDropTM 1000 Spectrophotometer (Thermo Scientific, MA, USA). $2 \mu \mathrm{g}$ of RNA was reversely transcribed with the High-Capacity cDNA Reverse Transcription Kit, according to manufacturer's protocol (Applied Biosystems). To perform the real time PCR (RT-PCR), equal cDNA amounts of each animal were selected using as a reagent SYBR Green ${ }^{\circledR}$ qPCR Master Mix (K0253, Pierce, Thermo Fisher Scientific) in a Step One Plus ${ }^{\mathrm{TM}}$ Real-Time PCR System (Applied Biosystems). Samples were run by triplicate and data were normalized to Gapdh. Primers of detected genes are detailed in Table 3.

\section{Statistical analysis}

Differences between animals/samples were analyzed by two-way ANOVA, comparing two variables (treatment and diet). In this test, when the interaction between 2 factors was not significant, statistical values were represented through \# where \# $\mathrm{p}<0.05$, \#\# $\mathrm{p}<0.01$, \#\#\# $\mathrm{p}<0.001$ and \#\#\#\# $\mathrm{p}<0.0001)$. When significant interaction was obtained, Tukey's post-hoc test was performed to compare the different groups where significant values were represented by * $\left({ }^{*} \mathrm{p}<0.05\right.$. ** $\mathrm{p}<0.01$, *** $\mathrm{p}<0.001$ and $* * * \mathrm{p}<0.0001)$. All data are presented as mean $\pm \mathrm{SEM}$, in the Graph Pad 6.0 Prism software (Graph Pad Software Inc., San Diego, CA, USA).

\section{Results}

\section{DXI treatment ameliorates HFD-related peripheral} alterations in APP/PS1 mice

In order to evaluate the effect of DXI treatment on metabolic parameters after HFD intake in APP/PS1 mice, firstly, body weight measurement and IP-GTT and IP-ITT were performed and immediately protein level of molecules involved in insulin signaling pathway were evaluated. Two-way ANOVA of the weight gain revealed a significant effect of diet $(\mathrm{p}<0.0001)$ and treatment $(\mathrm{p}<0.05)$ with interaction between both variables $(\mathrm{p}<0.05)$. As expected, animals fed with HFD showed a significant increase of body weight compared to those fed with conventional chow ( $p>0.0001$ for non-treated animals; $\mathrm{p}<0.05$ for treated animals). Surprisingly, mice fed with HFD and treated with DXI significantly reduced this parameter reaching values similar to animals fed with normal chow $(p>0.05)$ (Fig. 1A). Moreover, the weight gain observed in APP/ PS1 HFD mice was accompanied by alterations in peripheral glucose metabolism in both, IP-GTT and IPITT. As previously described by our group and also by

Table 3 Genes analyzed by RT-PCR

\begin{tabular}{lll}
\hline Gene & Forward & Reverse \\
\hline Atf3 & CTGGAGATGTCAGTCACCAAGTCT & TTTCTCGCCGCCTCCTTT \\
Atf4 & AGCAAAACAAGACAGCAGCC & ACTCTCTTCTTCCCCCTTGC \\
Atf6 & TTTCAGGGCAGGGCCATT & CCCGGGACAAACAGGTCTT \\
Bip & CAGATCTTCTCCACGGCTTC & GCAGGAGGAATTCCAGTCAG \\
Chop & CGAAGAGGAAGAATCAAAAACCTT & GCCCTGGCTCCTCTGTCA \\
Gapdh & TCTACCCACGGGCAAGTTCAA & GGTTTCTCCAGGCGGCATGT \\
Ir & TGTCCCCAGAAAACCTCTTCA & AAGGGATCTTCGCTTTCGGG \\
Irst & ACGACACTTTGCCATTGCC & CCTTTGCCCGTTATGCAGC \\
\hline
\end{tabular}




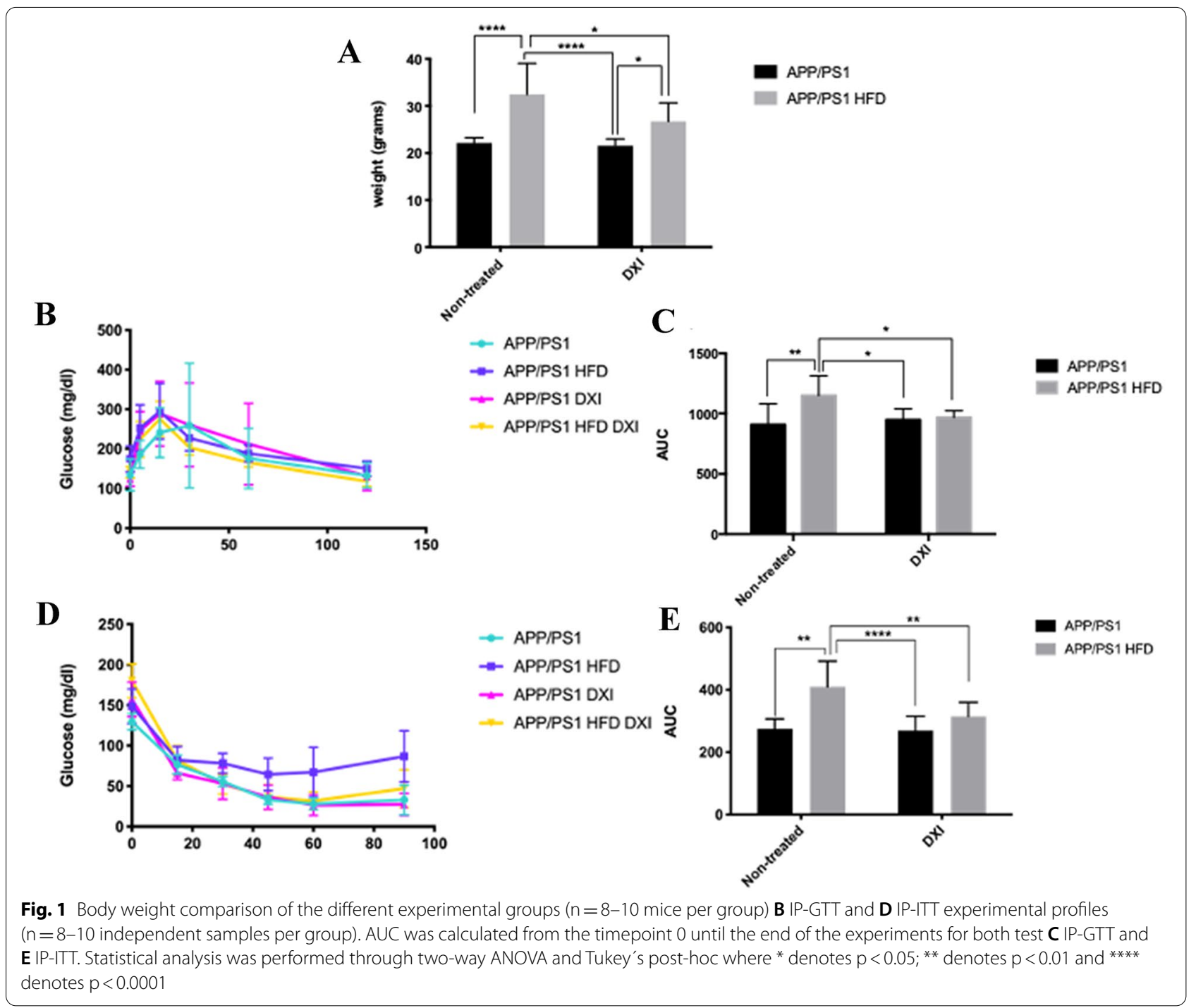

other authors [32, 37], two-way ANOVA showed a significant effect of diet in both test, IP-GTT and IP-ITT respectively $(\mathrm{p}<0.05 ; \mathrm{p}<0.0001))$, and in this last test also in the treatment factor $(\mathrm{p}<0.05)$ with interaction between both factors in both test $(\mathrm{p}<0.05 ; \mathrm{p}<0.05)$. Specifically, Tukey's post-hoc revealed that HFD intake induced a significant increase of fasting glucose levels in response to glucose and insulin intraperitoneal injection in comparison to mice fed with conventional chow ( $\mathrm{p}<0.01 ; \mathrm{p}<0.01$, respectively). By contrast, the results obtained in APP/PS1 HFD after DXI treatment were intriguing. While the glucose levels observed in APP/ PS1 HFD group pointed out metabolic disturbances, animals fed with the same diet but with an additional DXI treatment showed a significant decrease of fasting glucose levels in both test, IP-GTT and IP-ITT, compared to their controls ( $\mathrm{p}<0.05 ; \mathrm{p}<0.01)$, achieving glucose concentrations similar to those animals fed with conventional chow (Fig. 1B-E).

At molecular level, proteins involved in the insulin signaling pathway in liver were analyzed to confirm peripheral metabolic alterations. In line with observed previous data in this study, two-way ANOVA demonstrated a significant effect of treatment variable $(\mathrm{p}<0.0001)$ in phospho protein kinase $\mathrm{B}(\mathrm{p}-\mathrm{AKT})$ protein level. In the case of phospho glycogen synthase kinase 3 beta (p-GSK3 $\beta$ ), our data also showed a significant effect of treatment $(\mathrm{p}<0.001)$ with interaction between both variables $(p<0.01)$. Specifically, our data demonstrated a significant increase in APP/PS1 mice fed with HFD and treated to DXI group in comparison to non-treated group $(\mathrm{p}<0.001)$. However, although upward trend was 
observed in animals fed with conventional chow after DXI treatment, no significant differences were observed. Lastly, AKT and GSK3 $\beta$ did no show differences among experimental groups (Fig. 2).

\section{DXI treatment improves cognitive decline observed in both APP/PS1 mice fed with conventional chow and obesogenic diet}

In previous studies, it has been demonstrated that APP/PS1 mice showed cognitive decline in terms of spatial learning and memory $[30,38,39]$. Therefore, we evaluated whether DXI was able to rescue the cognitive impairment observed in this mice model through both tests, MWM and NORT. Regarding MWM, as it is shown in the Fig. 3A, B, the training performed by different groups showed an improvement of learning ability in those animals treated with DXI compared to non-treated animals. In line with these results, 2-way ANOVA analysis showed a significant effect of the treatment variable in the test day $(\mathrm{p}<0.01)$ independent of the diet that they had consumed (Fig. 3A, B). Moreover, results observed in the NORT after twoway ANOVA indicated a significant effect of both analyzed variables, treatment and diet $(\mathrm{p}<0.0001$; $\mathrm{p}<0.05)$ respectively, demonstrating that DXI treatment improves cognitive decline previously described by our group not only in transgenic animals fed with conventional chow [30] but also in those fed with HFD (Fig. 3C). No significant differences were observed on the speed among any of the groups of the test day. Therefore, results of scape latency were not due to differences in the swimming speed of the animals. These results are attached as supplementary material.

In order to support these results, an immunofluorescence assay against synaptophysin was carried out. In line with the results observed in the behavioral test, our results showed that the DXI treatment induced a substantial qualitative increase of this protein in the CA3 of the hippocampus compared to non-treated groups (Fig. 4A, B). In agreement with these results, the quantitative analysis of these images showed the significant effect of treatment variable $(\mathrm{p}<0.005)$ after the application of two-way ANOVA. Moreover, these data were corroborated with an enzymatic immunohistochemistry against drebrin (DBN1). As it can be observed in the image, mice treated with DXI showed a clear increase in

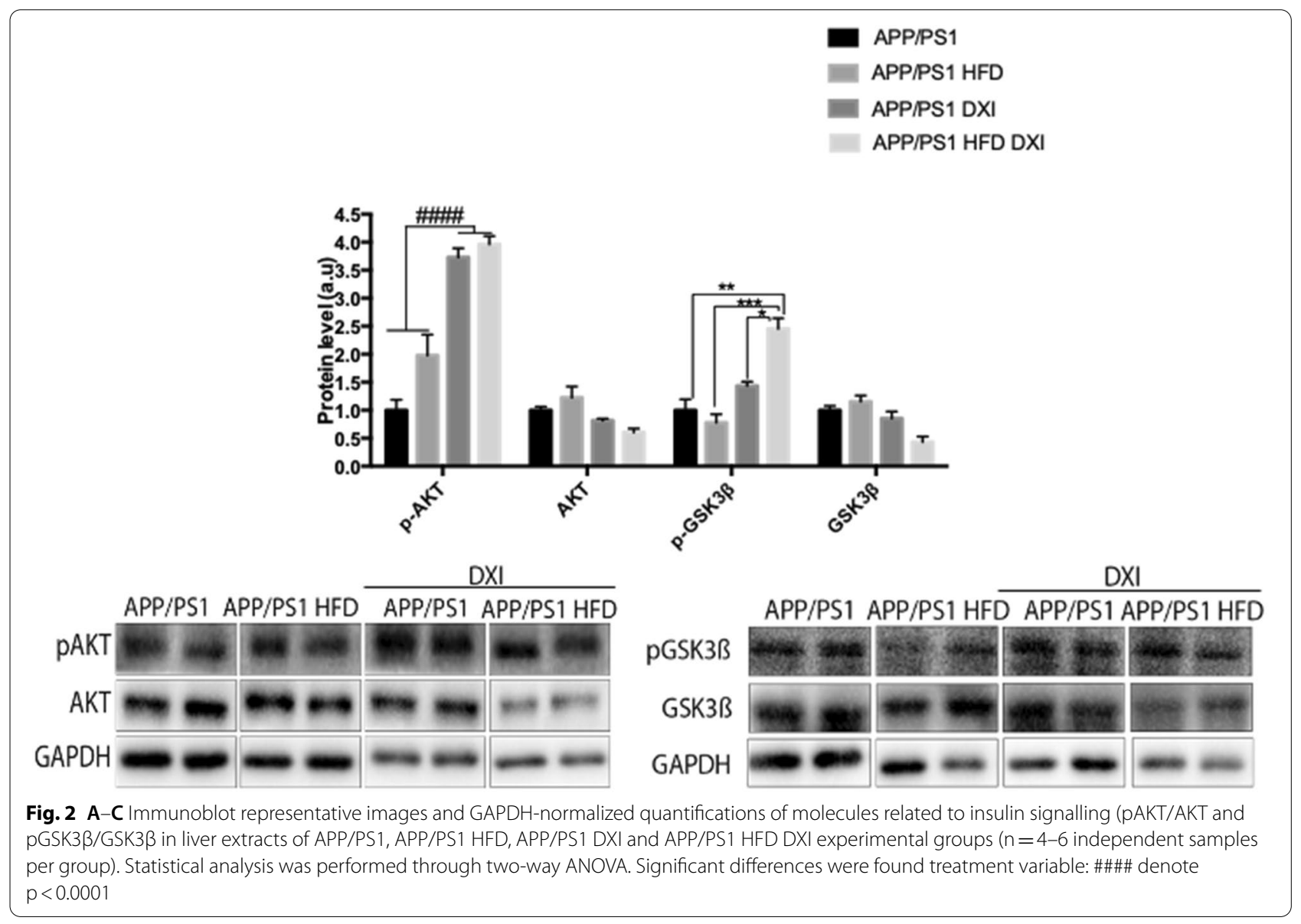




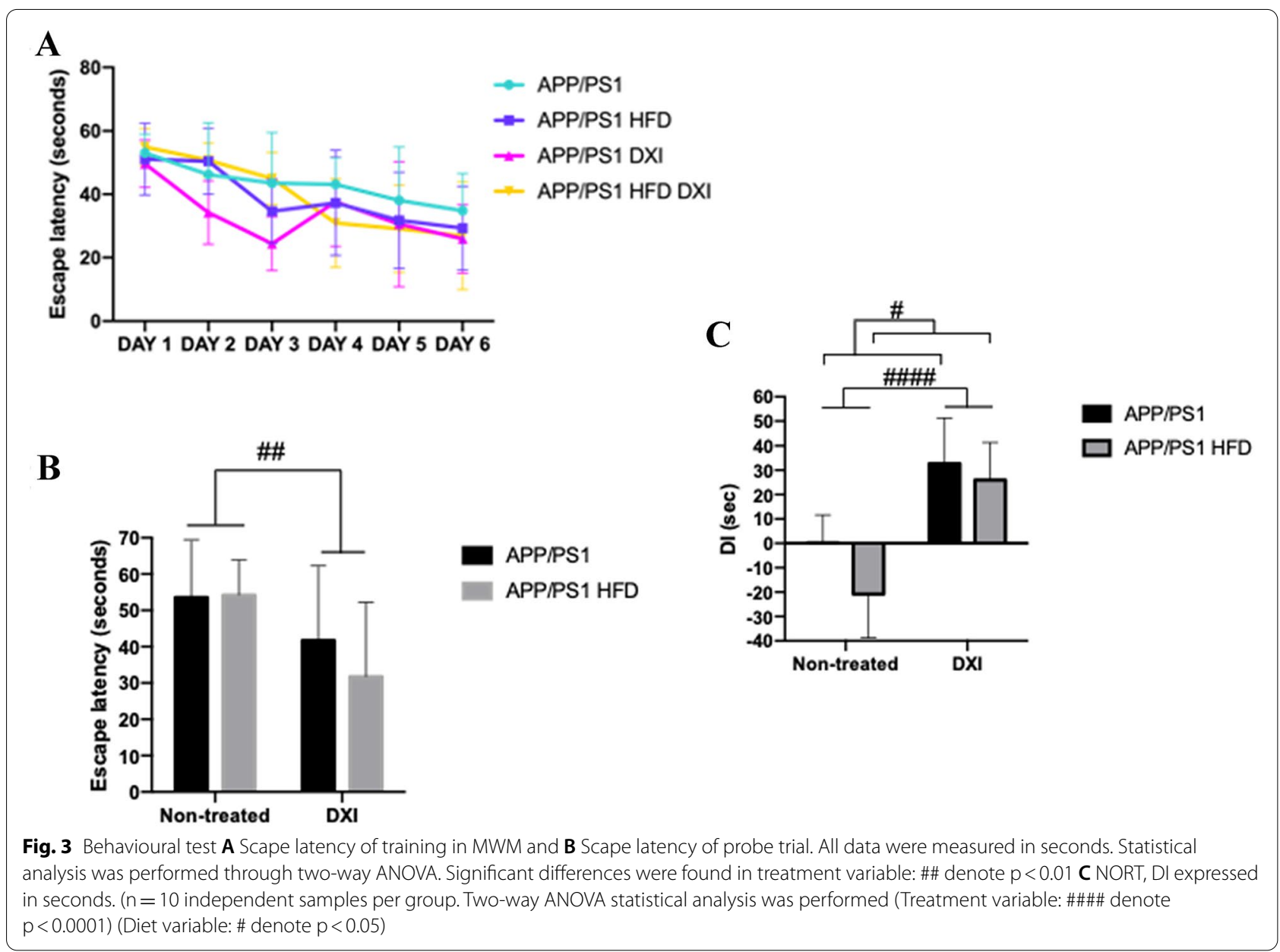

DBN1 protein level in CA3 and gyrus dentatus (GD) of the hippocampus (Fig. 4C).

\section{$D X I$ reduces $A \beta$-plaque burden in APP/PS1 mice fed with conventional chow and obesogenic diet}

It is widely demonstrated that APP/PS1 mice develop time-dependent accumulation of $A \beta$ plaques in the brain, which is enhanced with the obesogenic diet intake [40, 41]. To evaluate the effect of DXI on this process, S-thioflavin staining was performed for plaque detection. As expected, two-way ANOVA showed a significant effect of the diet $(p<0.0001)$ in the quantification of cortical $A \beta$ plaques deposition in APP/PS1 mice, demonstrating an increase of these plaques caused by HFD intake. Moreover, treatment factor also results in a significant effect $(\mathrm{p}<0.0001)$, indicating that long-term administration of DXI reduced $A \beta$ plaques deposition independent of the diet (Fig. 5A).

Likewise, Western blot analysis was carried out to evaluate the effect of DXI in non-amyloidogenic pathway, which is considered as the neuroprotective route
[42]. In correlation with previously showed data, twoway ANOVA of the results of pro-disintegrin and metalloproteinase domain-containing protein 10 (ADAM10) and ADAM10 protein levels revealed a significant effect of diet $(\mathrm{p}<0.001)$ and treatment $(\mathrm{p}<0.001)$, confirming that both factors alter the protein levels of this protein (Fig. 5B-D).

\section{DXI treatment reduces the neuroinflammatory response in APP/PS1 fed with conventional chow and obesogenic diet}

It is well known that neuroinflammation plays a key role in the development of $\mathrm{AD}[43,44]$, process which is exacerbated by the HFD intake [45-47]. In line with these previous data, two-way ANOVA of glial fibrillary acidic protein (GFAP) quantification indicated a significant implication of the treatment variable $(\mathrm{p}<0.0001)$ and diet variable $(\mathrm{p}<0.05)$ with interaction between both factors $(\mathrm{p}<0.05)$. Moreover, two-way ANOVA for ionized calcium binding adaptor molecule 1 (IBA1) protein levels demonstrated a significant effect of treatment 


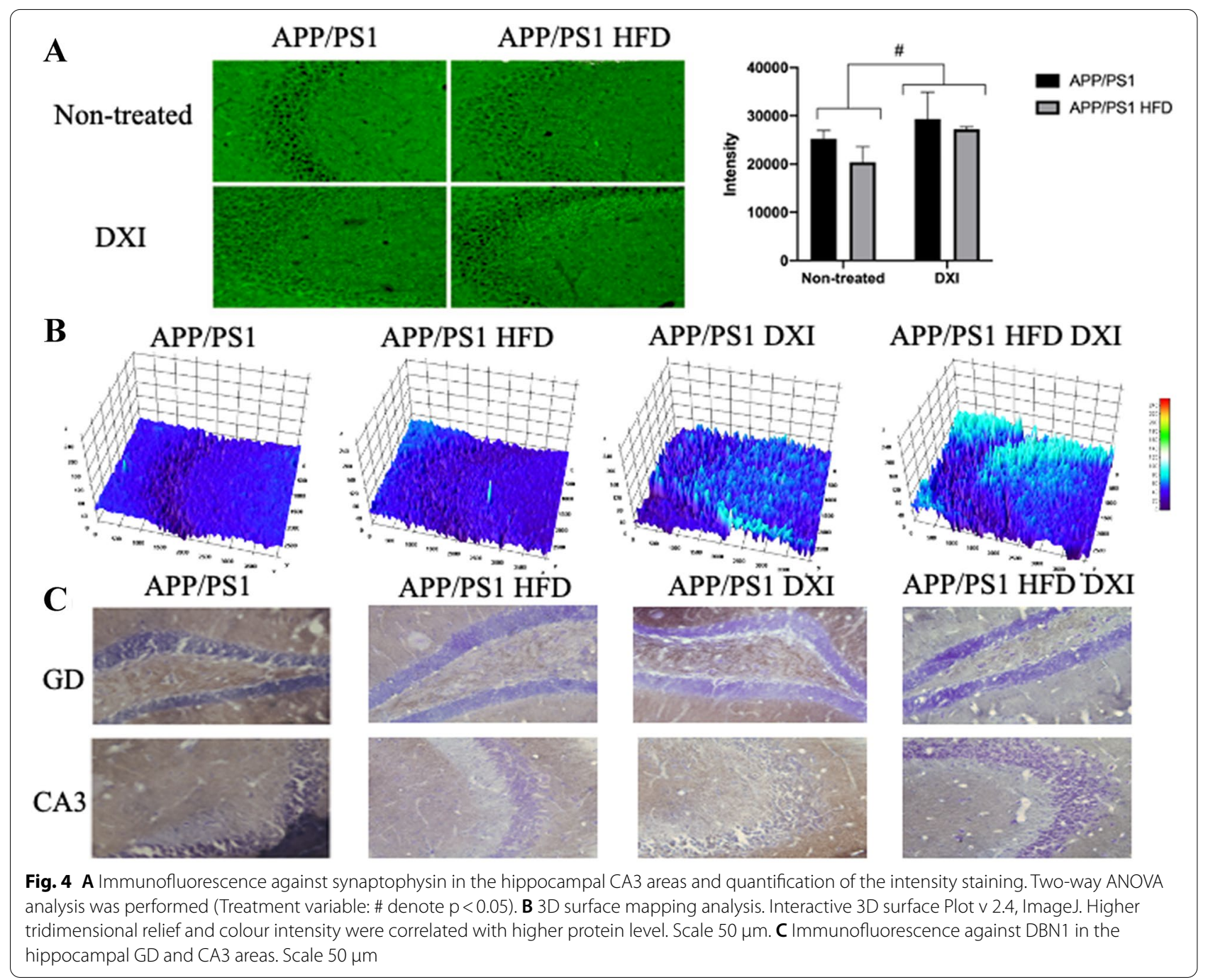

$(\mathrm{p}<0.0001)$ with interaction between both variables $(\mathrm{p}<0.01)$. Specifically, Tukey's post-hoc demonstrated that HFD consumption show a higher reactive profile when they were quantified by their covered area in APP/ PS1 fed with HFD compared to transgenic mice fed with conventional chow ( $<<0,05 ; \mathrm{p}<0,05$, respectively). By contrast, observed reactivity in both, astrocytes and microglia, was drastically decreased in response to DXI treatment independently of diet (GFAP: $p<0,001 \mathrm{APP} /$ PS1 vs APP/PS1 DXI; $\mathrm{p}<0.0001$ APP/PS1 HFD vs APP/ PS1 HFD DXI) and (IBA1: $\mathrm{p}>0.0001 \mathrm{APP} / \mathrm{PS} 1$ vs APP/ PS1 DXI; $\mathrm{p}<0.0001$ APP/PS1 HFD vs APP/PS1 HFD DXI) (Fig. 6A-D).

\section{DXI reduces endoplasmic reticulum stress}

Taking into account the involvement of endoplasmic reticulum stress in multiples pathologies among them in inflammatory processes [48] and metabolic disorders [49], we evaluated proteins involved in the main unfolded protein response (UPR) cascades such as inositol-requiring enzyme -1alpha (IRE1 $\alpha$ ) and eukaryotic initiation factor 2 alpha subunit (eI2F $\alpha)$. In this line, statistical analysis of pIRE1 $\alpha$ confirm a significant effect of treatment $(\mathrm{p}<0.01)$ previously described [49] with interaction between both factors $(\mathrm{p}<0.05)$. Tukey's post-hoc demonstrated that DXI treatment induced a significant decrease in pIRE1 $\alpha$ protein levels in APP/PS1 fed with obesogenic diet compared to their control $(p<0.01)$. However, in the case of animals fed with conventional chow, although DXI group showed a downward trend, the observed changes were not significant. Regarding to eI2F $\alpha$, in line with previous studies [50, 51], two-way ANOVA revealed a significant effect of diet and treatment in peI2F $\alpha$ protein levels in hippocampus $(\mathrm{p}<0.0001)$ and $\mathrm{p}<0.0001)$ respectively with interaction between both variables $(\mathrm{p}<0.0001)$. After Tukey's posthoc analysis, our results confirmed a significant increase 


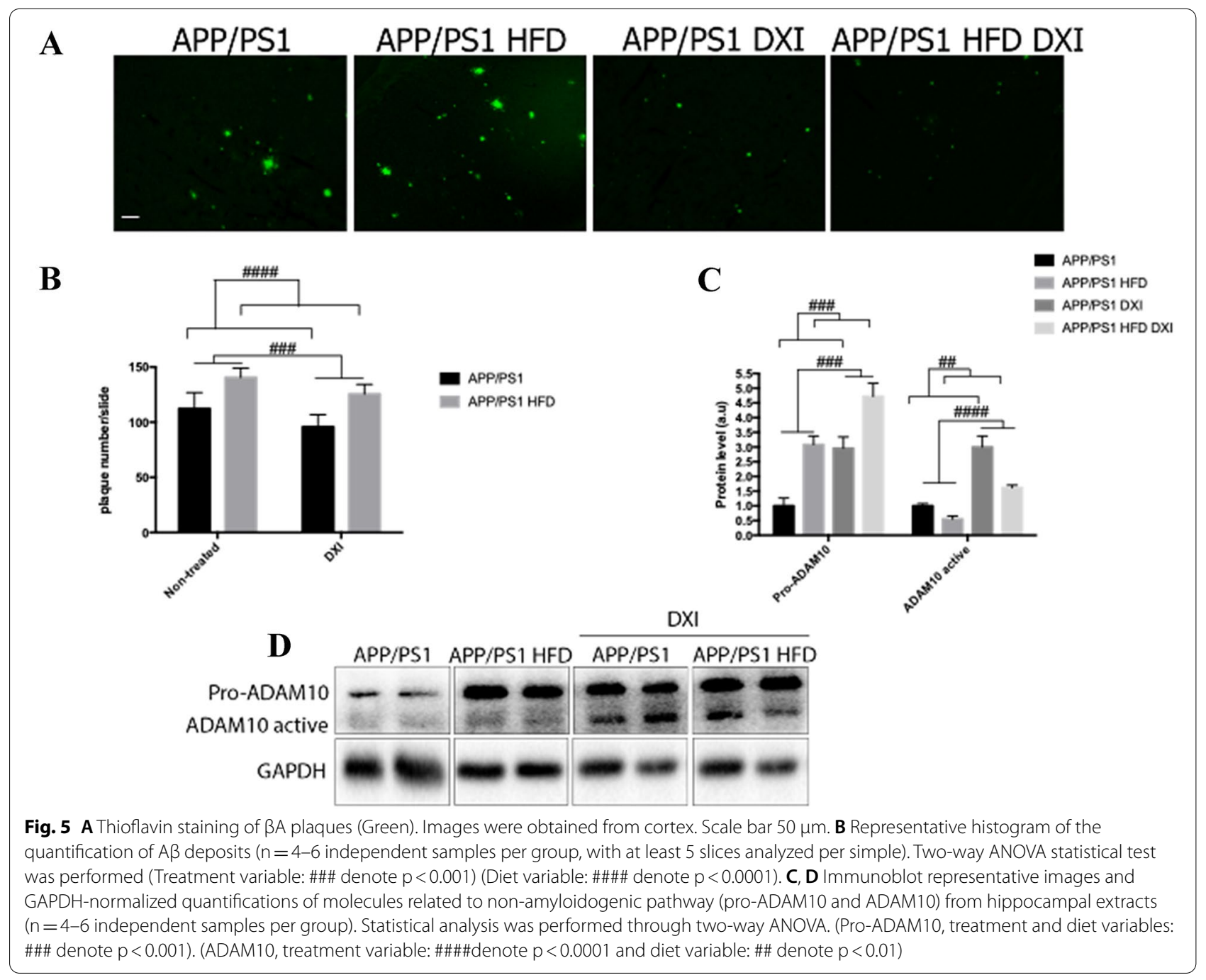

in the phosphorylated levels of this protein due to obesogenic intake in comparison to APP/PS1 mice fed with conventional chow $(\mathrm{p}<0.0001)$, effect which was completely reverted due to DXI treatment $(\mathrm{p}<0.0001)$. No significant effect of either diet nor treatment was observed in IRE1 $\alpha$ and eI2F $\alpha$ protein levels (Fig. 7A, B).

Regarding to mRNA expression, different transcript factors located downstream of IRE $1 \alpha$ and eI2F $\alpha$ in the UPR pathway were analyzed. In this context, no significant effect neither in diet nor treatment variable were observed in activating transcription factor 4 (Atf4) and activating transcription factor 6 (Atf6) mRNA expression. However, both of them showed interaction between both factors, $(\mathrm{p}<0.05)$ and $(\mathrm{p}<0.05)$ respectively. When analyzing C/EBP homologous protein (Chop, statistical analysis demonstrated a significant effect of diet in the expression of this molecule $(\mathrm{p}<0.05)$, confirming the alteration of UPR due to high fat diet intake. Finally, twoway ANOVA of the results of activating transcription factor 3 (Atf3) expression showed a significant effect of diet $(\mathrm{p}<0.001)$ and treatment $(\mathrm{p}<0.05)$ with interaction between both variables $(\mathrm{p}<0.05)$. Tukey's post-hoc multiple comparison indicated a significant increase in APP/ PS1 HFD DXI group compared to its control $(\mathrm{p}<0.05)$. No significant difference was observed in binding immunoglobulin protein (Bip) expression (Fig. 7C).

\section{DXI improves insulin signaling pathway APP/PS1 mice hippocampus}

In parallel, we evaluated mRNA expression profile of insulin repetor (Ir) and insulin receptor substrate 1 (Irs1) in the hippocampus due to HFD intake has not been only closely related to alterations in UPR pathway but also to insulin signaling disturbances [49]. Two-way ANOVA analysis revealed a significant effect not only in diet variable $(\mathrm{p}<0.05)$ but also in treatment variable $(\mathrm{p}<0.01)$ with interaction between both factors $(\mathrm{p}<0.05)$ in hippocampal Ir mRNA expression. Specifically, Tukey's post-hoc test indicated that $I r$ transcripts were 


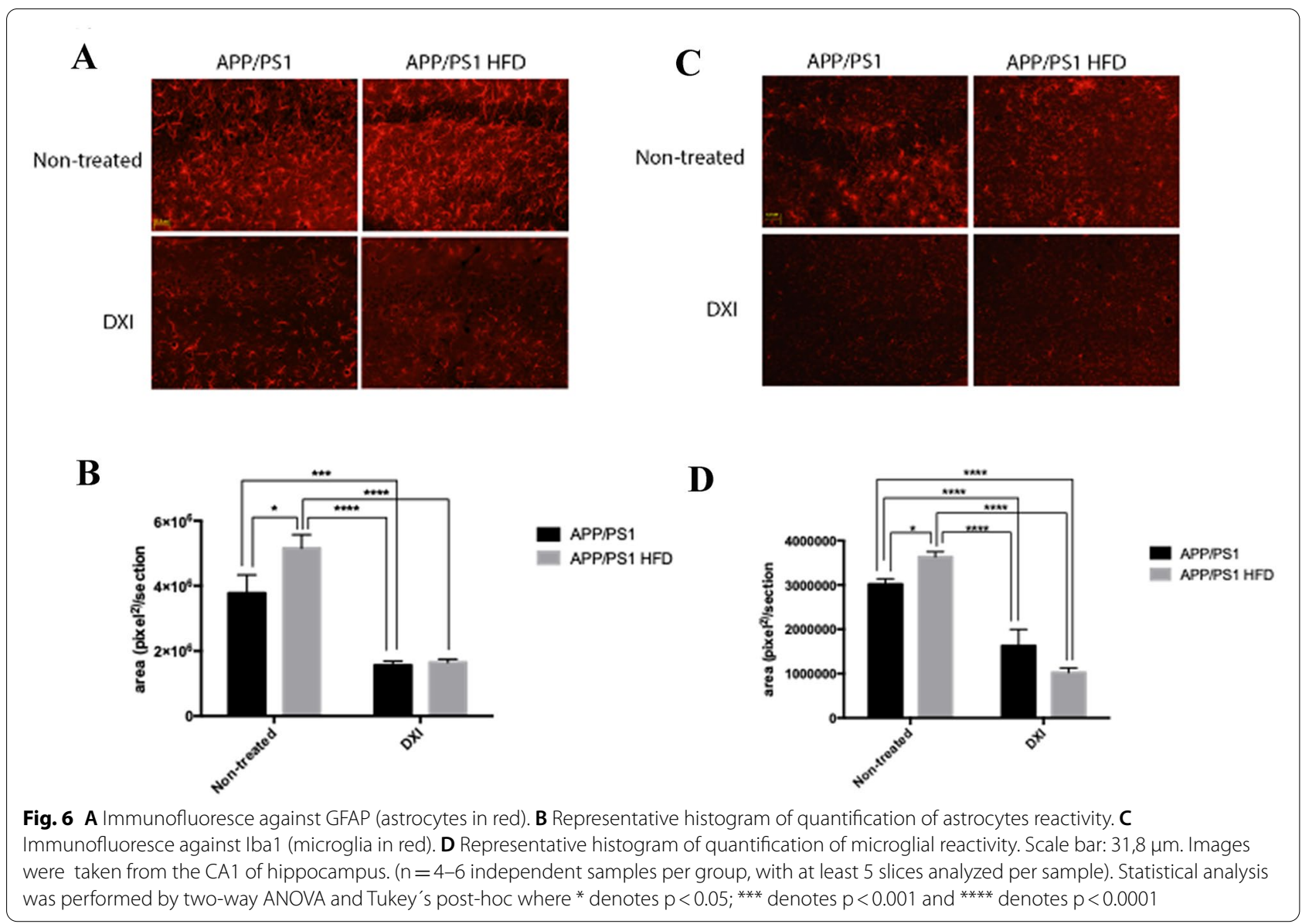

significantly increased in APP/PS1 animals treated with DXI in comparison to mice without treatment $(\mathrm{p}<0.05)$. Despite this, the effect was blocked by HFD intake (Fig. 8A).

Regarding protein levels, the immunoblotting analysis revealed a significant effect in hippocampal phospho insulin receptor substrate 2 (pIRS2) protein level of diet $(\mathrm{p}<0.05)$ and treatment $(\mathrm{p}<0.0001)$ with interaction between both factors $(p<0.05)$. Multiple comparison performed indicated a significant increase in pIRS2 in APP/PS1 mice induced by HFD intake $(\mathrm{p}<0.01)$. By contrast, these levels were drastically decreased after DXI treatment in both cases, HFD and conventional chowfed animals $(\mathrm{p}<0.01 ; \mathrm{p}<0.0001)$, respectively. In line with these results, our data demonstrated that DXI treatment induced a significant increase of pAKT protein levels independent of the diet that animals had consumed in the 2 way-ANOVA statistical analysis $(\mathrm{p}<0.001)$. AKT results were not significant (Fig. 8B, C).

\section{Discussion}

Several epidemiological studies have demonstrated that HFD intake is related to numerous pathologies such as obesity, T2DM and inflammation, all of them strongly involved in the development of cognitive loss in $\mathrm{AD}$ [5255], leading to be considered as a multifactorial disease. Thus, the neuroinflammatory process, associated mainly with microglial activation, could be the bridge between the peripheral initiation of a stress stimuli which will finally end with neuronal loss. In this context, the use of NSAIDs have been proposed as a possible therapeutic strategy to delay or stop the progression of this neurodegenerative disease. Likewise, different epidemiological studies have pointed out the benefits of chronic administration of NSAIDs in terms of reducing the risk for suffering late onset AD [56-59]. Nevertheless, they have not been able to fully achieve their objective, probably due to the late diagnosis of the pathology. Thus, in spite of being well known that inflammation plays a key role in the $\mathrm{AD}$, its contribution to the pathology has not been fully clarified. Our present study evaluates the effect of a chronic administration of DXI in the inflammatory process surrounded $\mathrm{AD}$ development, but also in the metabolic alterations such as weight gain, hyperglycemia and insulin resistance induced by HFD intake in APP/PS1 mice. These alterations directly affect the memory process, $A \beta$ 


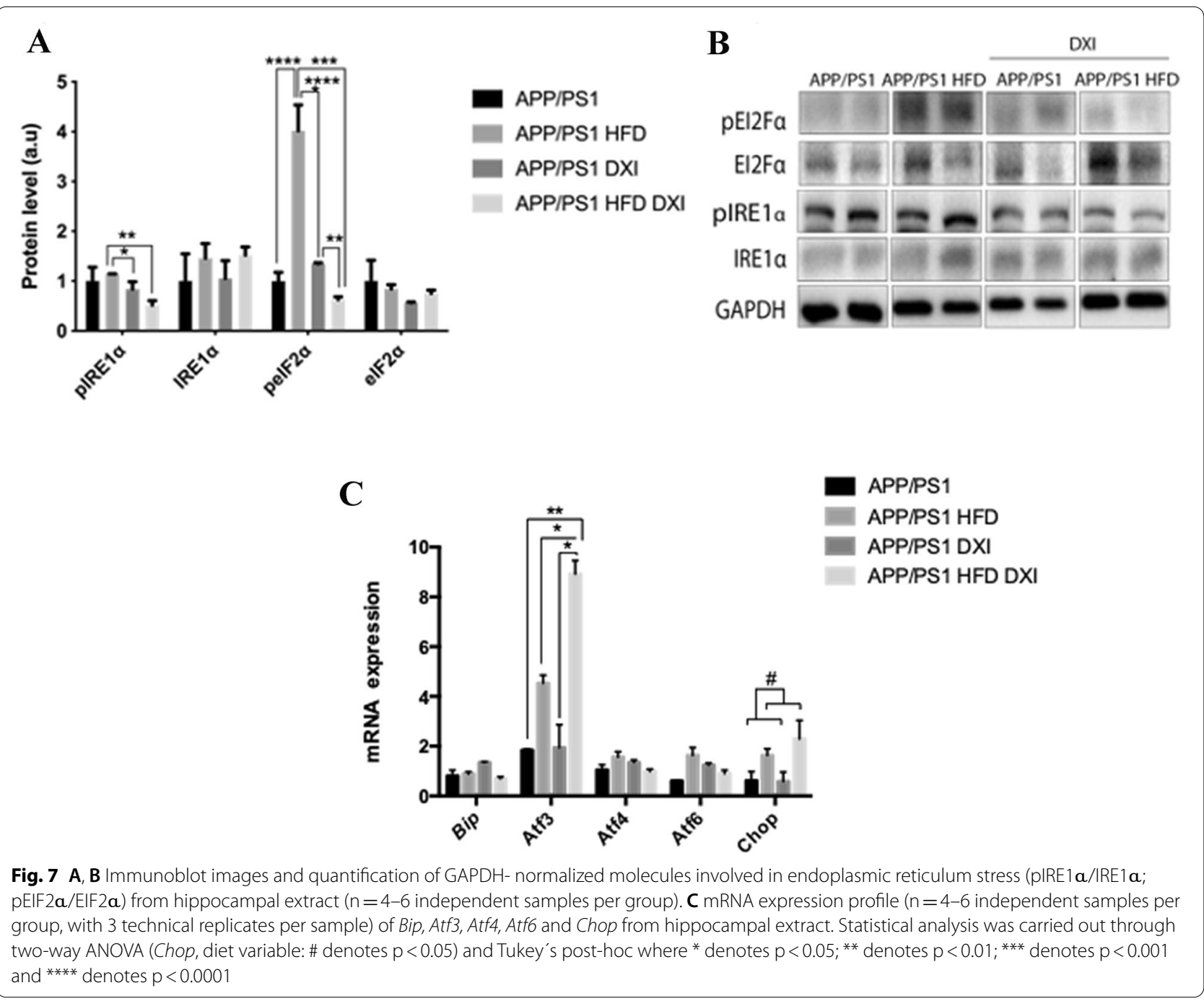

deposition, glial reactivity and UPR, as well as in insulin signaling pathway (Fig. 9).

Several studies have revealed that metabolic alterations constitute a high risk factor for the development of late onset $\mathrm{AD}[60,61]$. These findings have been the key in the approach of alternative point of view in terms of disease etiology and pathophysiology. In this context, several authors have considered AD as a systemic pathology, where brain in not the only responsible of pathological alterations [62-64]. In fact, it has been demonstrated that insulin resistance is a shared hallmark feature of obesity, T2DM and neuropathological processes underlying cognitive aging and dementia [65], together with inflammation. The latter, as it has been previously discussed, plays a key role in these pathological processes [66]. In line with this, there are epidemiological evidence suggesting a correlation between inflammation and insulin resistance state, where it has been described that obesity and the concomitant development of inflammation are the main contributors of insulin resistance. Likewise, studies in human obesity and insulin resistance have revealed a clear relation between chronic administration of proinflammatory signaling pathways and decreased insulin sensitivity [67-69]. In accordance with these results, our results confirm that the chronic administration of DXI reduces weight gain, glucose and insulin impaired response and insulin signaling pathway alterations in liver induced by HFD intake in APP/PS1 mice, reverting the metabolic alterations tightly associated to $\mathrm{AD}$ development.

Conversely, it is well known that brain gliosis activation plays an essential role in both, the development of all neurodegenerative disorders and metabolic disorders [70]. In fact, several studies have remarked that neuroinflammation is a clear feature of the pathology which is highly enhanced after HFD consumption as it has been 


\section{A}

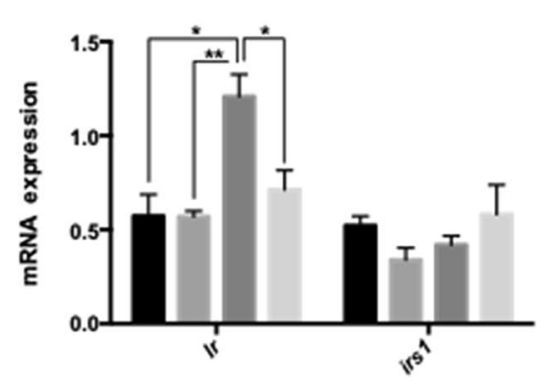

APPIPS1

APPIPS1 HFD

APP.PS1 DXI

APP/PS1 HFD DXI
B

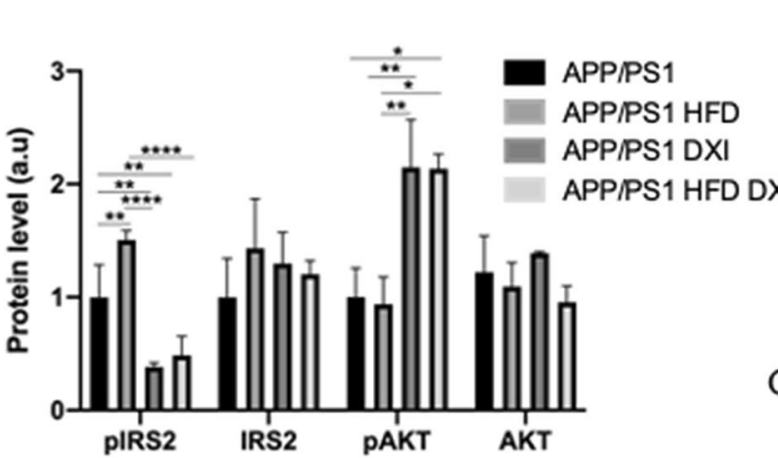

C

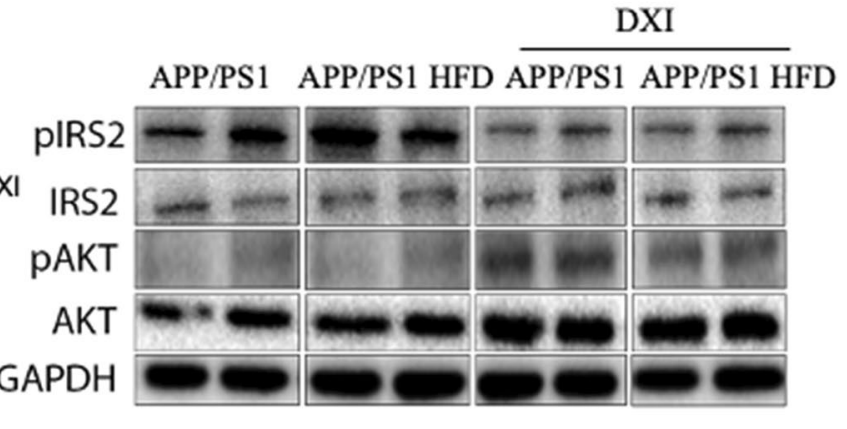

Fig. 8 A mRNA profile ( $n=4-6$ independent samples per group, with 3 technical replicates per sample) of Ir and Irs 1 from hippocampal extract. B, C Immunoblot images and quantification of GAPDH- normalized hippocampal molecules involved in insulin signalling pathway (pIRS2/IRS2; pAKT/ AKT) (4-6 independent samples per group). Two-way ANOVA was carried out and Tukey's post-hoc where * denotes $p>0.05 ;{ }^{* *}$ denotes $p<0.01$; **** denotes $\mathrm{p}<0.0001)$

demonstrated in our study and also by other research groups [71, 72]. Likewise, it has been described that neuroinflammatory process contributes to synaptic dysfunction and behavioral deficits in early stages of the disease $[73,74]$. In this context, our results demonstrate that the chronic administration of DXI drastically reduced the glial reactivity observed in both, APP/PS1 and APP/ PS1 HFD mice, leading to the restorage of synaptophysin, DBN1 and behavioral impairments. Regarding to the accumulation of $\mathrm{A} \beta$ oligomers, MacPherson and coworkers demonstrated that peripheral administration of tumor necrosis factor alpha (TNF $\alpha$ ) inhibitors modified the proinflammatory profile of AD mice, thus rescuing long term-potentiation together with the decrease of $\mathrm{A} \beta$ plaques [74]. In line with these previous results, our study confirms that the reduction of the inflammatory response also contributes to the reduction of $A \beta$ burden in the brain. Moreover, altogether confirms the study performed by Ho et al. and others, which demonstrated that preclinical $\mathrm{AD}$ animal models developed peripheral insulin resistance which coincide with the onset of $\mathrm{A} \beta$ accumulation in the brain, reinforcing the hypothesis that connect peripheral alterations with AD hallmarks [75-77].
At the molecular level, our study shows that chronic treatment with DXI increases drastically the active ADAM10 protein levels, which could be related with the $\mathrm{A} \beta$ plaques lowering and the cognitive improvement. In fact, ADAM10 has been proposed as a therapeutic target in terms of treating neurodegenerative conditions, including late onset $\mathrm{AD}$, given that its activity has been associated to neuroprotection through $A \beta$ plaques reduction [78]. Likewise, ADAM10 is considered as a relevant enzyme in the synapses since previous studies demonstrated its involvement in the re-modeling of the synaptic spines $[79,80]$. Moreover, in accordance with our data, it has been suggested that ADAM10 represents a new way to regulate excitatory neurons in the hippocampus which could explain the improvement observed in our mice after treatment.

It has been described that neuroinflammation also produces endoplasmic reticulum stress, thus leading to UPR disrupted activation [81]. In fact, Pintado and coworkers demonstrated that lipopolysaccharideinduced neuroinflammation produce UPR activation [81], leading to synaptic dysfunction, neuronal plasticity decrease and axonal alteration, all of them contributing to neurodegeneration [82]. In line with this association, chronic activation of the UPR has emerged 


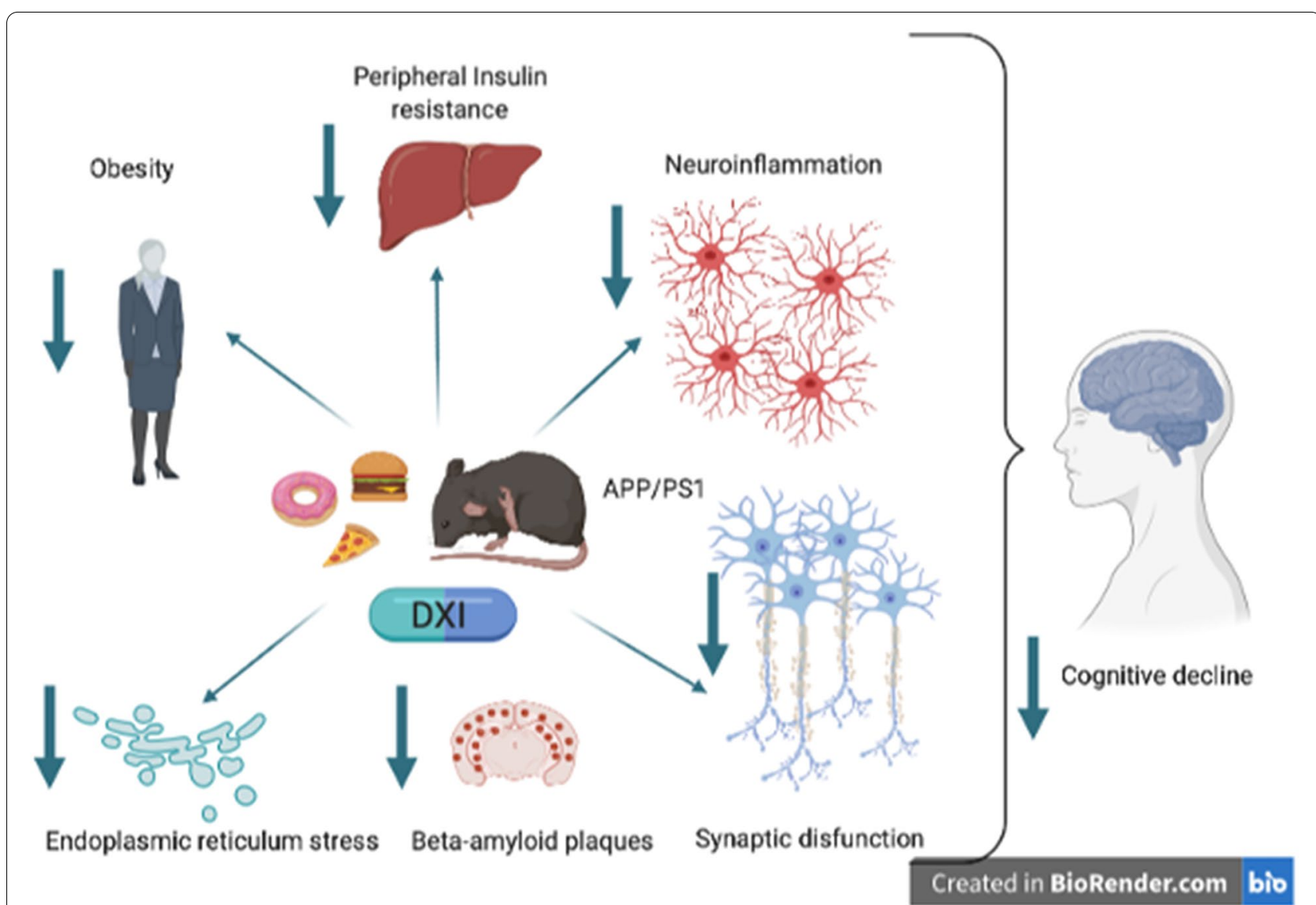

Fig. 9 Schematic diagram of the DXI effects. This drug may be an interest compound in the prevention of cognitive loss in AD due to its ability to act on different risk factors. In the present work, where APP / PS1 female mice suffer a metabolic stress associated with a HFD, we demonstrate that DXI improves peripheral parameters associated with insulin resistance. It also improves the cognitive process related to a decrease in the neuroinflammatory process, activation of the non-amyloidogenic pathway, improves the reticulum stress process in addition to parameters related to the synaptic process. All these results suggest that this drug could be used in a combinatorial therapy, for example associated with memantine and acetyl cholinesterase inhibitors for the prevention of late-onset AD

as a conserved feature among various neurodegenerative in both, animal models and post-mortem studies of tissues obtained from patients [83], neurodegenerative disorders which share an accumulation of specific misfolded proteins [84-86]. Specifically, in prion-infected mice, functional studies have demonstrated that sustained phosphorylation of eIF $2 \alpha$ dramatically reduces expression of synaptic proteins [87]. Likewise, its suppression has been associated with the relief of ADrelated plasticity and memory deficits, demonstrating that the chronic activation of this signaling has adverse effects on synaptic function [88, 89]. These previous data are in accordance with our results, since our data showed not only a significant increase in p-eIF $2 \alpha$ protein level in APP/PS1 mice fed with an obesogenic diet in comparison to APP/PS1 mice but also a significant reduction after DXI treatment. Moreover, animals treated with DXI showed a significant decrease in pIRE1 $\alpha$. Furthermore, these data corroborate the studies performed by Duran-Aniotz et al. [90] which demonstrated that the ablation of IRE $1 \alpha$ reduced the $A \beta$ deposition and synaptic and cognitive function restorage in $\mathrm{AD}$ mice models. Besides, these studies are in line with others which showed the fundamental involvement of this protein in pathological conditions. It is involved not only in neurodegenerative diseases but also in obesity, inflammation and T2DM, among others. Therefore, its inhibition could offer an interesting avenue for AD [91-93]. Going further, ATF3 is a stress-induced and adaptive-responsive gene located downstream of eIF $2 \alpha$ which basal levels are low. However, they can rapidly increase under stress [94, 95]. By contrast, its functions are variable depending on the context, where evidence demonstrates that NSAIDs induce ATF3 expression and activation, conferring neuroprotection through the inflammatory cytokines 
downregulation [95, 96] and promoting neural outgrowth [97]. In this context, our results supported these previous studies showing a significant increase in Atf3 mRNA expression in response to the stress caused by the obesogenic diet intake, which is drastically increased due to NSAIDs effect.

Finally, our study demonstrates a significant improvement in the hippocampus insulin signaling pathway, which is in accordance with this reported by Dasgupta and coworkers, who demonstrated that catestin improves insulin sensitivity by attenuating UPR through in silico and in vivo validation [98].

\section{Conclusions}

In summary, the present study confirms for the first time that DXI chronic administration in a mixed model of preclinical obesity associated T2DM and familial $\mathrm{AD}$, improved-related hallmarks associated to both diseases and modifying both central and peripheral targets involved in the development of AD. Our data strongly suggest that DXI could be a promising therapeutic strategy for the modification of the AD course. Due to the complexity of the disease and the multiple risk factors associated to its development where inflammatory process is key, we propose a combinatory therapy of different drugs considering essential the administration of NSAIDs with few side effects such as DXI with the aim to delay AD development (Additional file 1: Fig. S1).

\begin{abstract}
Abbreviations
AB: Amyloid beta; AD: Alzheimer's disease; ADAM10: Disintegrin and metalloproteinase domain -containing protein 10; AKT/ $\mathrm{p}$-AKT: Protein kinase $B /$ phospho- Protein kinase B; APP/PS1: APPswe/PS1dE9; Atf3: Activating factor 3; Atf4: Activating factor 4; Atf6: Activating factor 6; a.u.: Arbitrary units; Bip: Binding immunoglobulin protein; Chop: C/EBP homologous protein; DBN1: Drebrin; DI: Discrination index; DXI: Dexibuprofen; El2Fa/p- El2Fa: Eukaryotic initiation factor 2 a subunit/ phospho Eukaryotic initiation factor 2 a subunit; FBS: Fetal bovine serum; GAPDH: Glyceraldehyde 3-phosphate dehydrogenase; GD: Gyrus dentatus; GFAP: Glial fibrillary acidic protein; GKS3ß/ p-GKS3ß: Glycogen

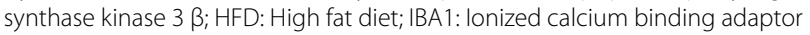
molecule 1; IBU: Ibuprofen; IP-GTT: Intraperitoneal-glucose tolerance test; IP-ITT: Intraperitoneal-insulin tolerance test; Ir: Insulin receptor; IRE1a/ p-IRE1a: Inositol-requiring enzyme-1a; Irs 1: Insulin receptor substrate 1; IRS2: Insulin receptor substrate 2; MWM: Morriw water maze; NSAID: Nonsteroidal antiinflammatory drug; NORT: Novel object recognition test; O/N: Over/night; PB: Phosphate buffer; PBS: Phosphate-buffered saline; PFA: Paraformaldehyde; RT-PCR: Real time PCR; T2DM: Type 2 Diabetes Mellitus; TNFa: Tumor necrosis factor a; UPR: Unfolded protein response.
\end{abstract}

\section{Supplementary Information}

The online version contains supplementary material available at https://doi. org/10.1186/s13578-021-00646-w.

Additional file 1: Fig. S1. Speed on the training day (no statistical differences were obtained)
Acknowledgements

Not applicable

\section{Authors' contributions}

ME proposal and schematization of the article, design the experiments, performed experiments, collected and analyzed the data, writing-original full draft, editing figures. ESL performed experiments, bibliography search, writing-original draft section. AM performed experiments, bibliography search, writing-original draft section. MC performed experiments, analyzed data, bibliography search, writing-original draft section. KH performed experiments, analyzed data, editing figures. PRM performed experiments, bibliography search. TE performed experiments, analyzed data. OB manuscript revision, bibliography search, linguistic correction. EV manuscript revision, experiment supervision. JO manuscript revision, linguistic correction. CA manuscript revision, experiment supervision. JF bibliography search. AC writing-original draft, proposal and schematization of the article, funding acquisition. All authors read and approved the final manuscript.

\section{Funding}

This work was supported by the Spanish Ministry of Economy and Competitiveness under the project SAF2017-84283-R, Biomedical Research Networking Centre in Neurodegenerative Diseases (CIBERNED) under project CB06/05/0024 and the European Regional Development Founds. AC [Amanda Cano] is supported by the Spanish Ministry of Science, Innovation and Universities under the Grant Juan de la Cierva (FJC2018-036012-I). PRM is supported by grants 2015/26084-1 and 2017/13224-5, São Paulo Research Foundation (FAPESP)—Brazil.

Availability of data and materials

All data generated or analysed during this study are included in this published article.

\section{Declarations}

\section{Ethics approval and consent to participate}

All the experiment on APP/PS1 transgenic mice were performed in accordance with the European Community Council Directive 86/609/EEC and the procedures were established by the Department d'Agricultura, Ramaderia i Pesca of the Generalitat de Catalunya.

\section{Consent for publication}

Not applicable.

\section{Competing interests}

The authors declare that they have no conflict of interest.

\section{Author details}

'Department of Pharmacology, Toxicology and Therapeutic Chemistry, Faculty of Pharmacy and Food Science, University of Barcelona, Barcelona, Spain. ${ }^{2}$ Biomedical Research Networking Centre in Neurodegenerative Diseases (CIBERNED), Madrid, Spain. ${ }^{3}$ Institute of Neuroscience, University of Barcelona, Barcelona, Spain. ${ }^{4}$ Institute of Nanoscience and Nanotechnology (IN2UB), University of Barcelona, Barcelona, Spain. ${ }^{5}$ Department of Pharmacy, Pharmaceutical Technology and Physical Chemistry, Faculty of Pharmacy and Food Science, University of Barcelona, Barcelona, Spain. ${ }^{6}$ Research Center and Memory Clinic, Fundació ACE. Institut Català de Neurociències Aplicades - International University of Catalunya (UIC), Barcelona, Spain. ${ }^{7}$ Department of Biochemistry and Biotechnology, Faculty of Medicine and Life Science, University Rovira I Virgili, Reus, Spain. ${ }^{8}$ Department of Cellular Biology, Physiology and Immunology, Faculty of Biology, University of Barcelona, Barcelona, Spain. ${ }^{9}$ Department of Gerontology, Federal University of São Carlos (UFSCar), São Carlos 13565-905, Brazil. ${ }^{10}$ Dominick P. Purpura Department of Neurosciences, Albert Einstein College of Medicine, New York City (10461), USA. ${ }^{11}$ Laboratory of Cellular and Molecular Pathology, Facultad de Ciencias de La Salud, Instituto de Ciencias Biomédicas, Universidad Autónoma de Chile, Talca, Chile.

${ }^{12}$ Unitat de Farmacologia I Farmacognòsia, Facultat de Farmàcia I Ciències de L'Alimentació, Universitat de Barcelona, Av. Joan XXIII 27/31, 08028 Barcelona, Spain. 
Received: 7 April 2021 Accepted: 4 July 2021

Published online: 22 July 2021

\section{References}

1. Ledesma M, Dotti C. Peripheral cholesterol, metabolic disorders and Alzheimer's Disease. Front Biosci (Elite Ed). 2012;4:181-94.

2. De Felice F. Alzheimer's Disease and insulin resistance: translating basic science into clinical applications. J Clin Invest. 2013;123(2):531-9.

3. Yaffe K, Haan M, Blackwell T, Cherkasova E, Whitmer RA, West N. Metabolic syndrome and cognitive decline in elderly latinos: findings from the Sacramento area latino study of aging study. J Am Geriatr Soc. 2007;55(5):758-62.

4. Raffaitin C, Feart C, Le Goff M, Amieva H, Helmer C, Akbaraly TN, et al. Metabolic syndrome and cognitive decline in French elders: the ThreeCity Study. Neurology. 2011;76(6):518-25.

5. Wolf PA, Beiser A, Elias MF, Au R, Vasan RS, Seshadri S. Relation of obesity to cognitive function: importance of central obesity and synergistic influence of concomitant hypertension. The Framingham Heart Study. Curr Alzheimer Res. 2007;4(2):111-6.

6. Jones S, Webeck G. The synergistic effects of APOE genotype and obesity on Alzheimer's Disease Risk. Int J Mol Sci. 2018;20(1):63.

7. Groeneveld O, Reijmer Y, Heinen R, Kuijf H, Koekkoek P, Janssen J, et al. Brain imaging correlates of mild cognitive impairment and early dementia in patients with type 2 diabetes mellitus. Nutr Metab Cardiovasc Dis. 2018;28(12):1253-60

8. Moran C, Phan TG, Chen J, Blizzard L, Beare R, Venn A, et al. Brain atrophy in type 2 diabetes: regional distribution and influence on cognition. Diabetes Care. 2013;36(12):4036-42

9. Ott A, Stolk RP, van Harskamp F, Pols HA, Hofman A, Breteler MM. Diabetes mellitus and the risk of dementia: the Rotterdam Study. Neurology. 1999:53(9):1937-42

10. de la Monte SM. Insulin resistance and neurodegeneration: progress towards the development of new therapeutics for Alzheimer's Disease. Drugs. 2017;77(1):47-65.

11. de la Monte SM. Type 3 diabetes is sporadic Alzheimer's disease: minireview. Eur Neuropsychopharmacol. 2014;24(12):1954-60.

12. Kandimalla R, Thirumala V, Reddy P. Is Alzheimer's Disease a type 3 diabetes? A critical appraisal. Biochim Biophys acta Mol basis Dis. 2017;1863(5):1078-89.

13. Vieira M, Ras L, De Felice F. Connecting Alzheimer's Disease to diabetes: underlying mechanisms and potential therapeutic targets. ENeuropharmacology. 2018;136(Pt B):160-71.

14. Steen E, Terry BM, Rivera EJ, Cannon JL, Neely TR, Tavares R, et al. Impaired insulin and insulin-like growth factor expression and signaling mechanisms in Alzheimer's disease —is this type 3 diabetes? J Alzheimers Dis. 2005;7(1):63-80.

15. Moloney AM, Griffin RJ, Timmons S, O'Connor R, Ravid R, O'Neill C. Defects in IGF-1 receptor, insulin receptor and IRS-1/2 in Alzheimer's disease indicate possible resistance to IGF-1 and insulin signalling. Neurobiol Aging. 2010;31(2):224-43.

16. Bomfim TR, Forny-Germano L, Sathler LB, Brito-Moreira J, Houzel J-C, Decker $\mathrm{H}$, et al. An anti-diabetes agent protects the mouse brain from defective insulin signaling caused by Alzheimer's disease- associated $A \beta$ oligomers. J Clin Invest. 2012;122(4):1339-53.

17. Clark I, Atwood C, Bowen R, Paz-Filho G, Vissel B. Tumor necrosis factorinduced cerebral insulin resistance in Alzheimer's disease links numerous treatment rationales. Pharmacol Rev. 2012;64(4):1004-26.

18. Wu J, Fu B, Lei H, Tang YW. Gender differences of peripheral plasma and liver metabolic profiling in APP/PS1 transgenic AD mice. Neuroscience. 2016:332:160-9.

19. Viola K, Klein W. Amyloid $\beta$ oligomers in Alzheimer's disease pathogenesis, treatment, and diagnosis. Acta Neuropathol. 2015;129(2):183-206.

20. Paouri E, Georgopoulos S. Systemic and CNS inflammation crosstalk: implications for Alzheimer's Disease. Curr Alzheimer Res. 2019;16(6):559-74.

21. in t'Veld BA, Ruitenberg A, Hofman A, Launer LJ, van Duijn C, Stijnen T, et al. Nonsteroidal antiinflammatory drugs and the risk of Alzheimer's disease. N Engl J Med. 2001;345(21):1515-21.
22. Stewart W, Kawas C, Corrada M, Metter E. Risk of Alzheimer's disease and duration of NSAID use. Neurology. 1997;48(3):626-32.

23. Ozben T, Ozben S. Neuro-inflammation and anti-inflammatory treatment options for Alzheimer's disease. Clin Biochem. 2019;72:87-9.

24. Eriksen J, Sagi S, Smith T, Weggen S, Das P, McLenon D, et al. NSAIDs and enantiomers of flurbiprofen target gamma-secretase and lower Abeta 42 in vivo. J Clin Invest. 2003:112(3):440-9.

25. Singer F, Mayrhofer F, Klein G, Hawel R, Kollenz C. Evaluation of the efficacy and dose-response relationship of dexibuprofen ( $(+)$-ibuprofen) in patients with osteoarthritis of the hip and comparison with racemic ibuprofen using the WOMAC osteoarthritis index. Int J Clin Pharmacol Ther. 2000;38(1):15-24.

26. Sánchez-López E, Egea MA, Cano A, Espina M, Calpena AC, Ettcheto M, et al. PEGylated PLGA nanospheres optimized by design of experiments for ocular administration of dexibuprofen-in vitro, ex vivo and in vivo characterization. Colloids Surf B Biointerfaces. 2016:145:241-50.

27. Zhang X, Liu X, Gong T, Sun X, Zhang Z. In vitro and in vivo investigation of dexibuprofen derivatives for CNS delivery. Acta Pharmacol Sin. 2012;33(2):279-88.

28. Moore RA, Derry S, McQuay HJ. Single dose oral dexibuprofen [S(+)ibuprofen] for acute postoperative pain in adults. Cochrane database Syst Rev. 2009;(3):CD007550.

29. Jin D-Q, Sung J-Y, Hwang YK, Kwon KJ, Han S-H, Min SS, et al. Dexibuprofen $(\mathrm{S}(+)$-isomer ibuprofen) reduces microglial activation and impairments of spatial working memory induced by chronic lipopolysaccharide infusion. Pharmacol Biochem Behav. 2008;89(3):404-11.

30. Ettcheto M, Sánchez-López E, Pons L, Busquets O, Olloquequi J, BeasZarate $C$, et al. Dexibuprofen prevents neurodegeneration and cognitive decline in APPswe/PS1dE9 through multiple signaling pathways. Redox Biol. 2017;13:345-52.

31. Jiao S-S, Bu X-L, Liu Y-H, Zhu C, Wang Q-H, Shen L-L, et al. Sex dimorphism profile of Alzheimer's disease-type pathologies in an APP/PS1 mouse model. Neurotox Res. 2016;29(2):256-66.

32. Ettcheto M, Sánchez-López E, Gómez-Mínguez Y, Cabrera H, Busquets $\mathrm{O}$, Beas-Zarate $\mathrm{C}$, et al. Peripheral and central effects of memantine in a mixed preclinical mice model of obesity and familial Alzheimer's disease. Mol Neurobiol. 2018;55(9):7327-39.

33. Cano A, Ettcheto M, Chang J-H, Barroso E, Espina M, Kühne BA, et al. Dual-drug loaded nanoparticles of Epigallocatechin-3-gallate (EGCG)/ Ascorbic acid enhance therapeutic efficacy of EGCG in a APPswe/PS1dE9 Alzheimer's disease mice model. J Control Release. 2019;301:62-75.

34. Ettcheto M, Petrov D, Pedrós I, Alva N, Carbonell T, Beas-Zarate C, et al. Evaluation of Neuropathological Effects of a High-Fat Diet in a Presymptomatic Alzheimer's Disease Stage in APP/PS1 Mice. J Alzheimer's Dis. 2016;54(1):233-51.

35. Busquets $\mathrm{O}$, Ettcheto $\mathrm{M}$, Pallàs $\mathrm{M}$, Beas-Zarate $\mathrm{C}$, Verdaguer E, Auladell $\mathrm{C}$, et al. Long-term exposition to a high fat diet favors the appearance of $\beta$-amyloid depositions in the brain of C57BL/6J mice. A potential model of sporadic Alzheimer's disease. Mech Ageing Dev. 2017;162:38-45.

36. Castro-Torres RD, Landa J, Rabaza M, Busquets O, Olloquequi J, Ettcheto $\mathrm{M}$, et al. JNK isoforms are involved in the control of adult hippocampal neurogenesis in mice, both in physiological conditions and in an experimental model of temporal lobe epilepsy. Mol Neurobiol. 2019;56(8):5856-65.

37. Petrov D, Pedrós I, Artiach G, Sureda FX, Barroso E, Pallàs M, et al. High-fat diet-induced deregulation of hippocampal insulin signaling and mitochondrial homeostasis deficiences contribute to Alzheimer disease pathology in rodents. Biochim Biophys Acta - Mol Basis Dis. 2015;1852(9):1687-99.

38. Guo HB, Cheng YF, Wu JG, Wang CM, Wang HT, Zhang C, et al. Donepezil improves learning and memory deficits in APP/PS1 mice by inhibition of microglial activation. Neuroscience. 2015;290:530-42.

39. Cao K, Xiang J, Dong Y-T, Xu Y, Li Y, Song H, et al. Exposure to fluoride aggravates the impairment in learning and memory and neuropathological lesions in mice carrying the APP/PS1 double-transgenic mutation. Alzheimers Res Ther. 2019;1 1(1):35.

40. Garcia-Alloza M, Robbins EM, Zhang-Nunes SX, Purcell SM, Betensky RA, Raju S, et al. Characterization of amyloid deposition in the APPswe/PS1dE9 mouse model of Alzheimer disease. Neurobiol Dis. 2006;24(3):516-24. 
41. Ramos-Rodriguez JJ, Ortiz-Barajas O, Gamero-Carrasco C, de la Rosa PR, Infante-Garcia C, Zopeque-Garcia N, et al. Prediabetes-induced vascular alterations exacerbate central pathology in APPswe/PS1dE9 mice. Psychoneuroendocrinology. 2014;48:123-35.

42. Kojro E, Fahrenholz F. The non-amyloidogenic pathway: structure and function of a-secretases. Subcell Biochem. 2005;38:105-27.

43. Zilka N, Ferencik M, Hulin I. Neuroinflammation in Alzheimer's disease: protector or promoter? Bratisl Lek Listy. 2006;107(9-10):374-83.

44. Editorial KA. Neuroinflammation and cognition. Front Aging Neurosci. 2018;10:413.

45. Lee YH, Hsu HC, Kao PC, Shiao YJ, Yeh SHH, Shie FS, et al. Augmented insulin and leptin resistance of high fat diet-fed APPswe/PS1dE9 transgenic mice exacerbate obesity and glycemic dysregulation. Int J Mol Sci. 2018;19(8):2333.

46. Medrano-Jiménez E, Jiménez-Ferrer Carrillo I, Pedraza-Escalona M, Ramírez-Serrano CE, Álvarez-Arellano L, Cortés-Mendoza J, et al. Malva parviflora extract ameliorates the deleterious effects of a high fat diet on the cognitive deficit in a mouse model of Alzheimer's disease by restoring microglial function via a PPAR- $\gamma$-dependent mechanism. J Neuroinflammation. 2019;16(1):143.

47. Timmermans S, Bogie J, Vanmierlo T, Lütjohann D, Stinissen P, Hellings N, et al. High fat diet exacerbates neuroinflammation in an animal model of multiple sclerosis by activation of the renin angiotensin system. J Neuroimmune Pharmacol. 2014;9(2):209-17.

48. Sprenkle NT, Sims SG, Sánchez CL, Meares GP. Endoplasmic reticulum stress and inflammation in the central nervous system. Mol Neurodegener. 2017;12(1):42.

49. Pandey VK, Mathur A, Kakkar P. Emerging role of Unfolded Protein Response (UPR) mediated proteotoxic apoptosis in diabetes. Life Sci. 2019;216:246-58.

50. Rocha M, Diaz-Morales N, Rovira-Llopis S, Escribano-Lopez I, Bañuls C, Hernandez-Mijares A, et al. Mitochondrial dysfunction and endoplasmic reticulum stress in diabetes. Curr Pharm Des. 2016;22(18):2649-2649.

51. Back SH, Kaufman RJ. Endoplasmic reticulum stress and type 2 diabetes. Annu Rev Biochem. 2012;81:767-93.

52. Jayaraj RL, Azimullah S, Beiram R. Diabetes as a risk factor for Alzheimer's disease in the Middle East and its shared pathological mediators. Saudi J Biol Sci. 2020;27(2):736.

53. Kacî̃ová $M, Z$ meškalová $A$, Kořínková L, Železná B, Kuneš J, Maletínská L. Inflammation: major denominator of obesity, Type 2 diabetes and Alzheimer's disease-like pathology? Clin Sci. 2020;134(5):547-70.

54. Elsworthy RJ, Aldred S. The effect of age and obesity on platelet amyloid precursor protein processing and plasma markers of oxidative stress and inflammation. Exp Gerontol. 2020;132:110838.

55. Sharma G, Parihar A, Talaiya T, Dubey K, Porwal B, Parihar MS. Cognitive impairments in type 2 diabetes, risk factors and preventive strategies. J Basic Clin Physiol Pharmacol. 2020. https://doi.org/10.1515/ jbcpp-2019-0105.

56. McGeer PL, Rogers J, McGeer EG. Inflammation, antiinflammatory agents, and Alzheimer's Disease: the last 22 years. J Alzheimer's Dis. 2016;54(3):853-7.

57. McGeer PL, Schulzer M, McGeer EG. Arthritis and anti-inflammatory agents as possible protective factors for Alzheimer's disease: a review of 17 epidemiologic studies. Neurology. 1996;47(2):425-32.

58. ADAPT. Cardiovascular and cerebrovascular events in the randomized, controlled Alzheimer's disease anti-inflammatory prevention trial. PLoS Clin Trials. 2006;1 (7):e33.

59. Zandi PP, Anthony JC, Hayden KM, Mehta K, Mayer L, Breitner JCS. Reduced incidence of AD with NSAID but not $\mathrm{H} 2$ receptor antagonists: the Cache County Study. Neurology. 2002;59(6):880-6.

60. van der Velpen V, Teav T, Gallart-Ayala H, Mehl F, Konz I, Clark C, et al. Systemic and central nervous system metabolic alterations in Alzheimer's disease. Alzheimers Res Ther. 2019;11(1):93.

61. Schwartz MW. Diabetes, obesity, and the brain. Science. 2005;307(5708):375-9.

62. Troncone L, Luciani M, Coggins M, Wilker EH, Ho C-Y, Codispoti KE, et al. $A \beta$ amyloid pathology affects the hearts of patients with Alzheimer's disease: mind the heart. J Am Coll Cardiol. 2016;68(22):2395-407.

63. Xiang Y, Bu X-L, Liu Y-H, Zhu C, Shen L-L, Jiao S-S, et al. Physiological amyloid-beta clearance in the periphery and its therapeutic potential for Alzheimer's disease. Acta Neuropathol. 2015;130(4):487-99.
64. Wang J, Gu BJ, Masters CL, Wang Y-J. A systemic view of Alzheimer disease - insights from amyloid- $\beta$ metabolism beyond the brain. Nat Rev Neurol. 2017;13(10):612-23.

65. Kullmann $S$, Heni M, Hallschmid M, Fritsche A, Preissl H, Häring H-U. Brain insulin resistance at the crossroads of metabolic and cognitive disorders in humans. Physiol Rev. 2016;96(4):1169-209.

66. Gaspar JM, Baptista Fl, Macedo MP, Ambrósio AF. Inside the diabetic brain: role of different players involved in cognitive decline. ACS Chem Neurosci. 2016;7(2):131-42.

67. Roytblat L, Rachinsky M, Fisher A, Greemberg L, Shapira Y, Douvdevani $A$, et al. Raised interleukin-6 levels in obese patients. Obes Res. 2000;8(9):673-5.

68. Straczkowski M, Dzienis-Straczkowska S, Stêpieñ A, Kowalska I, Szelachowska M, Kinalska I. Plasma interleukin-8 concentrations are increased in obese subjects and related to fat mass and tumor necrosis factor-alpha system. J Clin Endocrinol Metab. 2002;87(10):4602-6.

69. Sartipy P, Loskutoff DJ. Monocyte chemoattractant protein 1 in obesity and insulin resistance. Proc Natl Acad Sci. 2003;100(12):7265-70.

70. Nguyen JCD, Killcross AS, Jenkins TA. Obesity and cognitive decline: role of inflammation and vascular changes. Front Neurosci. 2014;8:375.

71. Spencer SJ, D'Angelo H, Soch A, Watkins LR, Maier SF, Barrientos RM. Highfat diet and aging interact to produce neuroinflammation and impair hippocampal-and amygdalar-dependent memory. Neurobiol Aging. 2017;58:88-101.

72. Duffy CM, Hofmeister JJ, Nixon JP, Butterick TA. High fat diet increases cognitive decline and neuroinflammation in a model of orexin loss. Neurobiol Learn Mem. 2019;157:41-7.

73. Chung W-S, Welsh CA, Barres BA, Stevens B. Do Glia drive synaptic and cognitive impairment in disease? Nat Neurosci. 2015;18(11):1539.

74. Li JJ, Dolios G, Wang R, Liao F-F. Soluble beta-amyloid peptides, but not insoluble fibrils, have specific effect on neuronal microRNA expression. PLoS ONE. 2014;9(3):e90770.

75. Ho L, Qin W, Pompl PN, Xiang Z, Wang J, Zhao Z, et al. Diet-induced insulin resistance promotes amyloidosis in a transgenic mouse model of Alzheimer's disease. FASEB J. 2004;18(7):902-4.

76. Pedersen WA, Flynn ER. Insulin resistance contributes to aberrant stress responses in the Tg2576 mouse model of Alzheimer's disease. Neurobiol Dis. 2004;17(3):500-6.

77. Luchsinger JA, Tang M-X, Shea S, Mayeux R. Hyperinsulinemia and risk of Alzheimer disease. Neurology. 2004;63(7):1187-92.

78. Peron R, Vatanabe IP, Manzine PR, Camins A, Cominetti MR. Alphasecretase ADAM10 regulation: insights into Alzheimer's disease treatment. Pharmaceuticals. 2018;11(1):12.

79. Malinverno M, Carta M, Epis R, Marcello E, Verpelli C, Cattabeni F, et al. Synaptic localization and activity of ADAM10 regulate excitatory synapses through N-cadherin cleavage. J Neurosci. 2010;30(48):16343-55.

80. Manzine PR, Ettcheto M, Cano A, Busquets O, Marcello E, Pelucchi S, et al. ADAM10 in Alzheimer's disease: Pharmacological modulation by natural compounds and its role as a peripheral marker. Biomed Pharmacother. 2019;113:108661.

81. Pintado C, Macías S, Domínguez-Martín H, Castaño A, Ruano D. Neuroinflammation alters cellular proteostasis by producing endoplasmic reticulum stress, autophagy activation and disrupting ERAD activation. Sci Rep. 2017;7(1):8100.

82. Hetz C, Saxena S. ER stress and the unfolded protein response in neurodegeneration. Nat Rev Neurol. 2017;13(8):477-91.

83. Scheper W, Hoozemans JJM. The unfolded protein response in neurodegenerative diseases: a neuropathological perspective. Acta Neuropathol. 2015;130(3):315-31.

84. Soto C. Unfolding the role of protein misfolding in neurodegenerative diseases. Nat Rev Neurosci. 2003;4(1):49-60.

85. Aguzzi A, O'Connor T. Protein aggregation diseases: pathogenicity and therapeutic perspectives. Nat Rev Drug Discov. 2010;9(3):237-48.

86. Kaushik S, Cuervo AM. Proteostasis and aging. Nat Med. 2015;21(12):1406-15.

87. Moreno JA, Radford H, Peretti D, Steinert JR, Verity N, Martin MG, et al. Sustained translational repression by elF2a-P mediates prion neurodegeneration. Nature. 2012;485(7399):507-11.

88. Ma T, Trinh MA, Wexler AJ, Bourbon C, Gatti E, Pierre P, et al. Suppression of elF2a kinases alleviates Alzheimer's disease-related plasticity and memory deficits. Nat Neurosci. 2013;16(9):1299-305. 
89. Yang W, Zhou X, Zimmermann HR, Cavener DR, Klann E, Ma T. Repression of the elF2a kinase PERK alleviates mGluR-LTD impairments in a mouse model of Alzheimer's disease. Neurobiol Aging. 2016;41:19-24.

90. Duran-Aniotz C, Cornejo VH, Espinoza S, Ardiles ÁO, Medinas DB, Salazar $C$, et al. IRE1 signaling exacerbates Alzheimer's disease pathogenesis. Acta Neuropathol. 2017;134(3):489-506.

91. Maly DJ, Papa FR. Druggable sensors of the unfolded protein response. Nat Chem Biol. 2014;10(11):892-901.

92. RiazTA, Junjappa RP, Handigund M, Ferdous J, Kim H-R, Chae H-J. Role of endoplasmic reticulum stress sensor IRE1 a in cellular physiology, calcium, ROS signaling, and metaflammation. Cells. 2020;9(5):1160,

93. Morita S, Villalta SA, Feldman HC, Register AC, Rosenthal W, HoffmannPetersen IT, et al. Targeting ABL-IRE1 a signaling spares ER-stressed pancreatic $\beta$ cells to reverse autoimmune diabetes. Cell Metab. 2017;25(4):883-897.e8.

94. Sato A, Nakama K, Watanabe H, Satake A, Yamamoto A, Omi T, et al. Role of activating transcription factor 3 protein ATF3 in necrosis and apoptosis induced by 5-fluoro-2'-deoxyuridine. FEBS J. 2014;281(7):1892-900.

95. Huang C-Y, Chen J-J, Wu J-S, Tsai H-D, Lin H, Yan Y-T, et al. Novel link of anti-apoptotic ATF3 with pro-apoptotic CTMP in the ischemic brain. Mo Neurobiol. 2015;51(2):543-57.
96. Thompson MR, Xu D, Williams BRG. ATF3 transcription factor and its emerging roles in immunity and cancer. J Mol Med. 2009;87(11):1053-60.

97. Seijffers R, Allchorne AJ, Woolf CJ. The transcription factor ATF-3 promotes neurite outgrowth. Mol Cell Neurosci. 2006;32(1-2):143-54.

98. Dasgupta A, Bandyopadhyay GK, Ray I, Bandyopadhyay K, Chowdhury N, De RK, et al. Catestatin improves insulin sensitivity by attenuating endoplasmic reticulum stress: In vivo and in silico validation. Comput Struct Biotechnol J. 2020;18:464-81.

\section{Publisher's Note}

Springer Nature remains neutral with regard to jurisdictional claims in published maps and institutional affiliations.
Ready to submit your research? Choose BMC and benefit from:

- fast, convenient online submission

- thorough peer review by experienced researchers in your field

- rapid publication on acceptance

- support for research data, including large and complex data types

- gold Open Access which fosters wider collaboration and increased citations

- maximum visibility for your research: over $100 \mathrm{M}$ website views per year

At BMC, research is always in progress.

Learn more biomedcentral.com/submissions 